\title{
CZECH CULTURAL STANDARDS FROM THE PERSPECTIVE OF THE TOP MANAGEMENT OF GERMAN COMPANIES
}

\section{Kňap, K., Nový, I.}

The goal of article is to analyze the analytical tools applied in the identification of national cultures and to identify and schematically express these Czech cultural standards, which are perceived most strongly by Germans when dealing with Czechs in higher-middle management. The article consists of a review of the related literature extended by a polemic on the applicability of the models. The authors conducted qualitative research based on semi-standardized interviews with ten German managers who grew up in the territory of former West Germany and had worked in the Czech Republic in international corporations for a period of at least two years. The results present three propositions connected to the most perceived cultural standards of Czech managers: propensity for improvisation, avoidance of conflict, and rejection of hierarchical structures.

Keywords: management; cultural standards; Czech Republic; Germany JEL classification: M12, M14

\section{Introduction}

The justification for the focus of this article is the significant involvement of German companies in the Czech economic environment. In 2016, goods were exported from the Czech Republic to Germany in the amount of 46.2 trillion Euros. This represents a third of the Czech Republic's total exports. German companies own over 9,000 firms in the Czech Republic (Hospodářské vztahy, 2016).

German managers working in key, top positions in subsidiaries are the bearers of their companies' visions and strategies. At the same time, they are the mediators of the culture of the organization they represent. Working on the other management levels are Czech managers, who are, in some way, guests in the given company culture defined by its owner.

Despite the historical and cultural proximity between the Czech Republic and Germany, mutual encounters between managers of these nationalities can give rise to conflicts, misunderstandings, and other types of problems and challenges linked to the occasionally failing communication and social interactions.

Communication between German and Czech employees has become the subject of a number of research studies, which have defined (and established) over the years a basic paradigm describing the typical behavior of Germans and Czechs in the work environment.

The mutual perception of individual attributes of behavior has been described, among others, by the so-called "cultural standards". These standards have been defined over the course of the last two decades by the leading authors (Nový \& Schroll-Machl, 2005, 2007, 2015; Thomas, 1996, 2001) on this issue.

The goal of this article is the analysis of the analytical tools applied in the identification of national cultures and, furthermore, the identification and schematic expression of those Czech cultural standards that are perceived most strongly by Germans when dealing with Czechs in higher and higher-middle management. 
In regard to the character of this goal, qualitative research has been chosen, based on the methodological approach of the "critical incident technique". The procedure of the selected research is based on the defined cultural differences between Germans and Czechs according to Thomas (1996).

The structure of the article is organized in the following manner: first, an overview of the relevant literature is provided, followed by the description of the research and data methodology; subsequently, a list of findings stemming from the performed research is provided. Finally, we present a discussion and a summary.

\section{Literature Review}

According to Nový and Schroll-Machl (2007), cultural anthropology, social psychology, and psychology continue to search for certain criteria by means of which they could clearly and coherently point out the crucial differences of individual national cultures. International companies search for means to effectively organize and manage teams made up of members originating from different cultures. This mainly involves seeking out criteria that can coherently and clearly point out and more tangibly capture the cultural differences of individual cultures. The companies are mainly concerned with the naming and transparency of these criteria, which could help to influence more effectively the interpersonal perception and communication in international teams. This is done mainly in order to increase the level of cooperation and mutual understanding among employees.

In many respects, the success of business negotiations depends on proper understanding. In addition to linguistic differences, which are not simple but in which the barrier of misunderstanding is evident, it is also necessary to overcome the barriers of various intercultural differences (Bedrnová \& Nový, 2009).

The existence of empirical intercultural studies on this matter is rather sporadic. Basically, there are two main scientific methodological approaches allowing us to identify, record, describe, and practically grasp the differences between national cultures. These approaches include G. Hofstede's method of cultural dimensions $(1980 ; 2001$; Hofstede \& Bond, 1988) and the qualitative method of the so-called "cultural standards", introduced by author Thomas $(1996,2001)$.

Some of the first intercultural studies include the works of Kluckhohn and Strodtbeck (1961). These, however, dealt more with human existence and essence than with the direct analysis of an individual of a certain culture. Therefore, in expressing differences in value dimensions, they addressed the following: (1) people's relationship to their environment - nature, i.e. the perception of how a given culture can influence its future. Furthermore, (2) time orientation, where a dimension describes whether a community is oriented more on the past, present, or future. The subsequent dimension is the definition (3) of human nature - the perception of one's own and the other's nature as inherently negative or, on the contrary, as honest and positive with occasional hesitation. The dimension of (4) orientation on activities expresses a focus on the value expression of one's existence, depending on one's own activity. The final dimension (5) is people's relationship towards others, with distinction being made whether an individualistic or a collective culture of decision-making or negotiation is involved in the given case.

The best-known and most cited works in the field of intercultural management are those by Hofstede (1980, 2001), which include his definitions of cultural differences defined by basic dimensions. 
His definition of cultural differences, defined by basic dimensions, is among the most utilized tools of quantitative research in this field. Research data were collected between 1967 and 1973 solely in IBM subsidiaries in sixty-four countries, interviewing in total more than 117,000 employees of IBM. The original purpose of the research was finding a tool to improve communication within this multinational, globally acting company. Afterwards, Hofstede decided to offer the results to the general public.

Hofstede's theoretical concept is oriented toward "basic values" that he depicts (or interprets) on the lowest levels of cultures. In comparison to standard national differences, cultural dimensions in work or in an organization are perceived as superficial on the level of symbols, heroes, and rituals. Initially, Hofstede defined four, then later five, dimensions of national cultures (Hofstede, 2016).

Dimension (1), power distance, is defined as "the accepted unequal degree of division of power of a country's culture by their less powerful members or organizations". The basic aspect of dimension (2), the degree of individualism or collectivism, is the degree of independence that a society maintains among its members. This dimension differentiates between an individual's self-perception in terms of "I" or "we".

A high score in dimension (3), the dominance of masculine or feminine values, is defined by the fact that society is ruled by mutual competition, goals, and success. A low (feminine) score in this dimension means that the dominant value in society is the support of others and the quality of life.

Dimension (4), the effort to avoid risk and uncertainty, relates to the way in which a society deals with the fact that the future is unpredictable. The final dimension, (5) short-term or long-term orientation, describes how societies maintain a connection to their pasts while dealing with the challenges of the present and future and the different ways in which they prioritize these two essential goals.

Hofstede is convinced that these patterns of behavior manifest themselves with strong persistence (endurance) and thus have a high level of resistance to change.

This idea was questioned by Beugelsdijk et al. (2015). The authors examined how country scores on Hofstede's dimensions have developed over time by replicating Hofstede's dimensions using data from the World Values Survey. Their results indicate that, on average, contemporary societies score higher on Individualism and Indulgence versus Restraint, and they score lower on Power Distance than do past societies. They found that cultural change is absolute rather than relative, meaning that countries' scores on the Hofstede dimensions relative to the scores of other countries have not changed very much.

The limitations to Hofstede's approach lie in the fact that his research was carried out almost exclusively in one organization (IBM) which, although it operated in a multicultural environment, can still be influenced by the culture of the organization itself. In addition, his research was done in an IT company that, although operating with an overlap into other business- and customer-oriented fields, offered only one type of product, which served as its symbol (hardware, software, and other connected services).

This assumption was evaluated by Schmitz and Weber (2014) who tested the validity of one particular dimension (uncertainty avoidance) on sample of German and French workers of a non-IT company and teachers. In total, 469 workers and teachers answered a questionnaire with 43 questions. The authors present criticism suspecting that the Uncertainty Avoidance dimension is specific to the Hofstede IBM sample. Consequently, 
this dimension is neither to be used as a standard of cross-national comparisons, nor as the basis for general descriptions about countries as wholes.

In same year, Minkov and Hofstede (2014) published a study which evaluated the same dimension (uncertainty avoidance). The study was based on 2010 Social Survey data for 25 European countries and Israel and the authors obtained, in contrary, a close replication of Hofstede's uncertainty avoidance with strong face validity, internal reliability, and similar predictive properties to those of the original measure. According to Minkov and Hostede, their replication and analysis elucidate the nature of uncertainty avoidance as a dimension of national culture and expose some misconceptions about it.

Furthermore, there are two other studies showing contrary results and conclusions. Venaik and Brewer (2013) warn of the Hofstede (and GLOBE) national culture dimension scores for analysis at the level of individuals and organizations. They distract from the value of such models and practical implication of the Hofstede's dimension scores which should not be used to infer individual/managerial and group/organizational level behavior and preferences.

In the same journal, De Mooij (2013) published a reaction to the above-mentioned paper. She points out several causes of misinterpretation, lack of understanding the basic differences between the models and ignorance of authors for the fundamental and conceptual differences which may cause the formulating of incorrect hypotheses.

It shows how Hofstede's work evokes extreme reactions. Many researchers use it as a paradigm for cross-national comparison, while other criticize it harshly.

The core of Hofstede's research is now more than 40 years old. It is possible to argue that, for instance, the post-Communist countries of Central and Eastern Europe have since then had to go through radical changes in the power of their individual dimensions. G. Hofstede also mentions this issue on his website with reference to constant updating.

Hofstede's work is not the only extensive analysis that exists on the issue. In 1994, House initiated the GLOBE program ("Leadership and Organizational Behaviour Effectiveness Research Program"). The GLOBE project was carried out by 150 researchers in 60 countries (House et al., 1999). The project followed directly in Hofstede's steps. A total of 17,000 respondents from 825 companies in 62 countries were questioned. The work was divided into respondents from three independent fields: the food industry, financial services, and telecommunications.

The basic dimension and methodology remained unchanged. Hofstede's work was basically expanded to include the following dimensions of national cultures: (6) assertiveness (expressiveness), (7) performance orientation and (8) humane orientation. Hofstede and Minkov (2010) criticized GLOBE's approach as an overly complicated use of research jargon in questionnaires and claimed it did not reflect the problems of managers on the "front lines". In addition, Hofstede mentions that GLOBE often used terms (or expressions) identical to those of Hofstede himself but used them in different meanings.

The results of the GLOBE project were used to create a model of clusters, i.e. concurrent managerial models of individual cultures (Gupta \& Hanges, 2004). Due to irrelevancy of the data, however, the Czech Republic was not included in the list.

American scientist Hall $(1985,1990)$ chose a method that, similar to Hofstede, defined specific cultural dimensions. Hall built more strongly off anthropological foundations and attempted to identify the fundamental dimensions of co-existence in terms of human cultures. 
As one of the primary dimensions defining cultural diversity Hall defined (1) space, i.e. perception of acceptable distance between individuals in direct discussion, which is variable throughout different cultures. The next dimension is (2) the perception of time, which he divides into monochronic and polychronic. He goes on to classify cultures as those with (3) high communication context, i.e. cultures that do not put such a heavy emphasis on uttered (textual) information and cultures with (4) low communication contexts, which communicate directly in full context.

Similar to Hall, Demorgon (1989) also attempted to describe all cultural dimensions linked to human activity. Like other authors, he defined a relatively large number of dimensions as (1) the organization of behavior linked to polychronic and monochronic perceptions of time, (2) attention, the counterparts of which are distracted and concentrated attention, (3) method of communication, which differentiates between two extreme planes, i.e. objective and subjective methods of expression (contextual expression), and (4) motivation for communication, in which Demorgon divides motivation to act as either orientation toward a task or orientation toward people, and so forth.

This is where we first encounter the definition of so-called "counterparts", i.e. methods of behavior that can be expressed through dimensions based on extreme values of human activity (behavior).

Thomas (2010) discusses this by using an example dealing with the dimension of (1) the organization of behavior. One can either act quickly, or with a maximum amount of foreknowledge. Carrying out both at the same time, however, is impossible. Theoretically, all activities (actions) may be carried out only in these two extremes.

Trompenaars (1993), a Dutch manager and consultant with international experience, focused on 10,000 managers of roughly 50 nationalities with a certain relationship toward Europe and its post-Communist countries, including former Czechoslovakia. Following the work of Hofstede and Hall, Trompenaars attempted to reach deeper into the analysis of cultural differences and more specifically identify the dimensions that were impacting the thinking and social behavior of members of various cultures. In his concept, dimensions were divided into three groups: (1) relationship toward others, (2) relationship toward time, and (3) relationship toward nature.

From these aforementioned dimensions, a total of seven basic dimensions of culture can be identified. Some of them are identical with Hofstede's dimensions, while the rest express slightly subtler divisions of cultural differences. In comparison with the GLOBE project, Trompenaars' concept intentionally avoided repeating Hofstede's dimensions. This was partially done in order to cast doubt on (or challenge) the quality of (Hofstede's) dominant qualifications at the time and also to verify whether the results of this old dimension could be replicated (Smith et al. 1996).

The conclusions that can be drawn from the studies and databases above are similar, despite the fact that these studies were carried out on various specimens and among various nations using different evaluation methods in different periods of time.

Basically all approaches directly or indirectly confirmed that the original and often challenged (or revised) global approach created by Hofstede is still present, and even globalization as such cannot wipe out Hofstede's defined "basic values", which are rooted in an individual and are depicted (interpreted) by Hofstede in the lowest levels of culture. 
In contrast to the authors above (Hofstede, 1980; Trompenaars, 1993; House, 1993; Hall, 1985), Thomas' (1996) concept, which is a typical "close-to-action" approach, defines typical "cultural standards".

Contrary to Thomas, other authors have dealt with the definition of cultural dimensions on certain levels (or scales) on which individual cultures are situated and which potentially also have their extreme characteristics (values) within these measuring scales.

According to Thomas, the definition of cultural standards has a slightly different concept and informative value. As a result of socialization, cultural standards are a natural part of an individual and as a rule become visible only in interaction with members of a different culture. Therefore, it is possible to fully identify and interpret them exclusively only in the process of confrontation of two specific cultures. Their characteristics only apply to these compared cultures. They do not represent a universal scale, but are the result of comparing specific cultures interpreted within their framework.

The resulting cultural standards of Germans will thus be different if we compare and analyze their interaction with Czechs than if we were to analyze German interaction with, for example, Italians.

A crucial (typical) distinguishing trait of this method is the method of gaining data and interpreting them (Reber et. al. 2004). Emphasis is not placed on interviews with informants from specific cultures (with the help of questionnaires), but on reporting (communicating) critical incidents (events) derived from their expectations during contact with another culture. The resulting scientific analysis of these incidents led to the formulation of perceived standards. Thus, it is not a general description of a foreign culture, but a definition of norms that are relevant for the interaction of two cultures and for the description of the differences between them.

Cultural standards represent a methodological tool so far most specifically revealing and characterizing particular ways of thinking, social behavior, and the work behavior of the members of individual cultures.

Fink et al. (2001) published a work defining Czech cultural standards in business cooperation. The empirical research mentioned in the article and the definition of cultural standards was based on the approach and defined standards according to Thomas (1996) with reference to the multi-perspective approach of Demorgon (1996).

The actual qualitative research investigated the definition of German and Czech cultural standards. In 1996 and 1997, 50 interviews were carried out in Germany, Czech Republic, and Austria exploring critical incidents in mutual business interaction. This work yielded roughly three hundred critical incidents from Czechs and Germans.

The result of this work from 1996 was a definition of categories, i.e. cultural standards that apply to Czech colleagues from the perspective of their German co-workers regardless of their employment position:

- $\quad$ fluctuating self-confidence

- $\quad$ orientation toward social relationships

- failure to differentiate between professional and private life

- rejection of structures

- avoidance of conflict

- propensity for improvisation 
The results of the studies and research express the cultural dimensions and cultural standards based on analysis of organizations throughout their hierarchy. The question of behavior on the level of middle and higher management still remains unanswered. Yet, Czech managers play an important role in German companies. For this reason, it is useful to know how their German counterparts may interpret Czech behavior on the level of upper-middle management. The goal is to gain information on the perception of Czech cultural standards on a managerial level from the perspective of German managers who have long-term experience in top posts in the Czech Republic. A specific goal is to ascertain and schematically express the Czech cultural standards on managerial level that appear significantly in critical incidents from the point of view of German managers. The research questions are as follows:

1. What Czech cultural standards from the perspective of German managers appear on the level of Czech top management?

2. Which of these cultural standards do German managers perceive the most intensely?

\section{Methods and Data}

The respondents were Germans in managerial positions who communicate, define company strategy and make decisions together with their Czech colleagues on the same hierarchical level. They were individuals who grew up on the territory of former West Germany. According to Hofstede and Minkov (2010), basic values are embedded in an individual by the country in which he/she was born and "socialized".

The next condition was that respondents had worked in the Czech Republic in an international corporation for a period of at least two years. Managers were selected from various fields (4x automotive industry, 2x automotive manufacturing, 1x energy, 1x consultancy, $1 \mathrm{x}$ construction industry, $1 \mathrm{x}$ insurance) in order to avoid the "double-up" effect. The selection of informants was carried out via "convenience sampling" and subsequently "snowball sampling". In the summer of 2016, a total of 10 interviews were carried out.

The type of research selected was qualitative research in the form of a semi-standardized narrative interview, defined by Thomas (1996). Semi-standardized "face-toface" interviews were conducted in the native language of the respondent. The interviews took place directly in the respondents' offices to ensure a "home environment".

The "critical incident technique" was used, i.e. social situations in which one of the negotiating parties was surprised or bewildered by the behavior of the other party or misunderstood the reasons for their behavior (Nový \& Schroll-Machl, 2007). The reason for the choice of this type of sociological research was an interest in expanding the existing concept based on the direct responses of the participants of such meetings in combination with the theoretical basis of intercultural issues.

In organizing the meetings, German managers were always informed of the intent to carry out the interview, during which they were to provide critical incidents from intercultural interactions with their direct Czech colleagues (managers). It was not our wish to surprise the respondents just before beginning the interview. The goal was that they should be prepared to tell three consistent stories from their professional lives.

Respondents were not asked in advance about specific cultural standards. They were only requested to tell three critical situations (stories) that most stuck in their minds. The Czech cultural standards emerged from the subsequent evaluation of the interviews. 
After the narration portion of the interview, the evaluator raised the question concerning the respondents' explanation of the critical incident, how they had coped with it, and what lessons they had learned for the future. The aim was to eliminate possible confusion between a cultural standard and a common workplace misunderstanding.

The interviews, which lasted between one and two hours, were recorded on recording devices and subsequently translated in full and transcribed into the Czech language (full recordings). A total of 15,112 words were transcribed. Further analysis of texts and evaluation of incidents and cultural standards was carried out in the Maxqda12 program.

The text was a subject of analysis. The approach was based on segmentation, or closed coding, during which segments or codes defined in advance were searched for (Czech cultural standards). A code was assigned to a segment or word. The authors assumed the role of evaluators. The method refers to Thomas' (2010) evaluation method: "results showing a high concurrence of indicators relating to behavior patterns can define a specific cultural standard". Czech cultural standards have been assigned 197 codes in total.

The results and the assignment of incidents to cultural standards were re-consulted with some of the interviewees, as well as with experts on the issue of intercultural conflicts and a during group discussion in a scientific panel. The incidents were also compared with the theoretical, cultural and historical explanations of Czech authors and experts on intercultural issues (Fink et al., 2001; Nový \& Schroll-Machl, 2005, 2007, 2015; Thomas, 1996, 2010).

\section{Results}

As shown in Table 1, the most frequently mentioned were events related to the three Czech cultural standards:

- Propensity for improvisation

- Avoidance of conflict

- Rejection of hierarchical structures

Table 1 | Czech cultural standards, coding results

\begin{tabular}{|ll|c|}
\hline & \multicolumn{1}{|c|}{ Cultural standard } & Total number of codes \\
\hline 1. & Fluctuating self-confidence & 4 \\
\hline 2. & Orientation toward social relationships & 18 \\
\hline 3. & Failure to differentiate between professional and private life & 8 \\
\hline 4. & Rejection of (hierarchical) structures & 30 \\
\hline 5. & Avoidance of conflict & 99 \\
\hline 6. & Propensity for improvisation & 33 \\
\hline
\end{tabular}

Source: Authors

In Table 2, the assignment of codes to individual respondents coming from particular interviews is shown. 


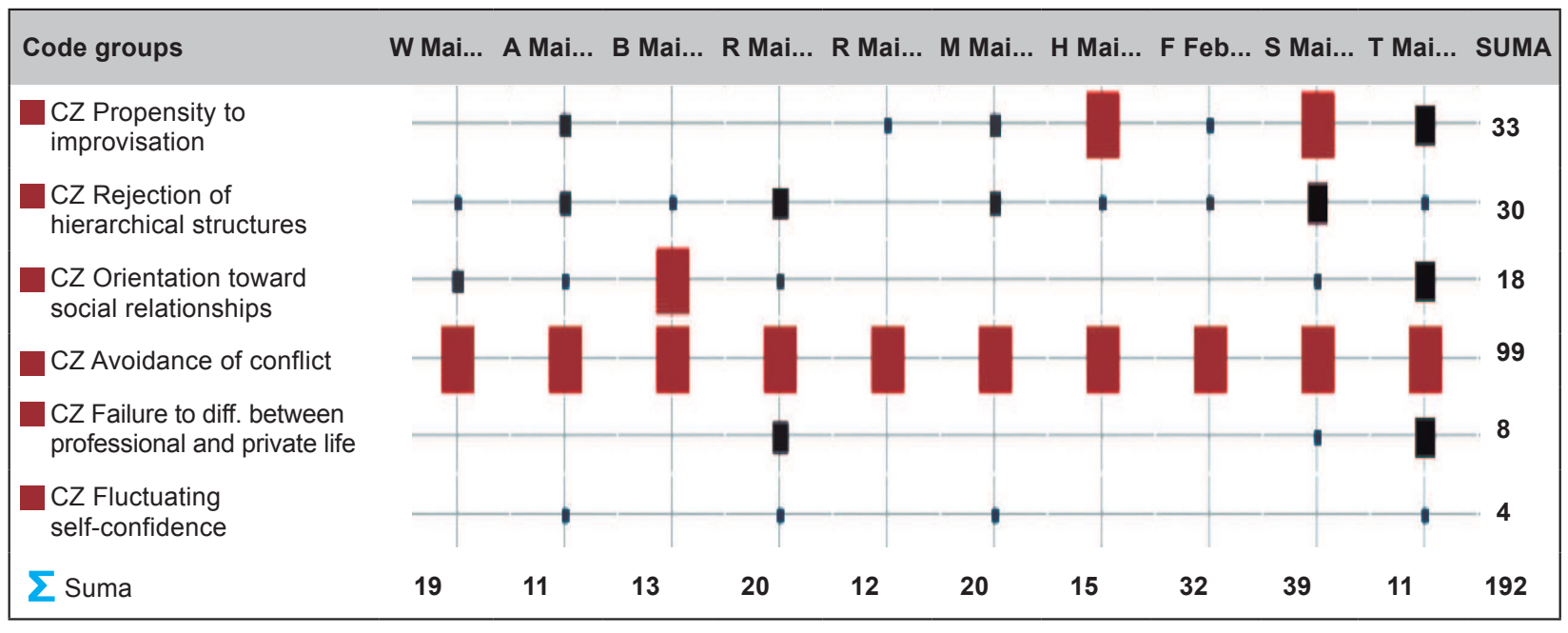

Source: Authors, Maxqda 12 evaluation in Czech language

All respondents were very open in their narrations. When describing the critical events, they expressed in advance their great respect for the expert knowledge of their Czech colleagues and the quality of their work. They pointed out in particular their Czech colleagues' abilities to improvise in a short time span and under pressure, to follow things through, to transform an idea into a creative solution, as well as goal orientation. The next sections present the most frequently mentioned concepts.

\subsection{Propensity for improvisation}

Propensity for improvisation was mentioned (coded) a total of 33 times. Examples from interviews point to an awareness of this strength, but they often also address what may be the reason for such a high occurrence of this standard.

"I think we are similarly structured. We Germans do not like surprises. We are hopeless at spontaneity or improvisation. This is something I have learned in the Czech Republic and a little bit in another country, but in the Czech Republic it was taken to perfection."

"You (Czechs) must solve the problem quickly. The method for doing so is derived over the course of action. We (Germans) would first debate how to do it, and then we would say how much time we need for it. It's just a completely different method."

"We have a colleague here (a Czech manager); he is sitting in his car on the way to a lecture in a neighboring country, calling his subordinate to ask him: 'Hey, make me a few slides'. That's what I call perfectionism in improvisation. This colleague doesn't even have time to see the slides. And the one preparing them is put under sudden, intense stress, which could have probably been avoided."

"Sometimes I think it's great what one can do in such a short time. But on the other hand, I can see that the quality suffers and so does satisfaction. You have a feeling then of being under permanent time pressure."

In this context, the respondents speculated about whether improvisation may sometimes actually be the result of inadequate planning. The wish to combine both approaches was repeatedly expressed, i.e. combining the Czech inclination to improvise with the Germans' excessive planning into a kind of middle path. 
Improvisation creates less pressure on planning. The standard is therefore also connected with a different perception of time. The Czech managers commented upon in the research tended toward the so-called polychronic perception of time (Demorgon, 1989), in which individual steps may not follow chronologically but several can be performed at the same time. Hall $(1985,1990)$ adds in this context that in polychronic oriented cultures, time flexibility is a prerequisite of work. Deadline collisions, interruptions, or operative interventions in project implementation are accepted. Trompenaars (1993) similarly expresses this dimension as a concurrent perception of time.

Czech managers also showed a tendency to focus on action (action orientation) as defined by Demorgon (1989). This dimension is linked again with the polychronic perception of time, when the result and quick completion of the task with the help of improvisation (if necessary) is preferred. Thus, in this case, not so much emphasis is laid on thorough planning and precise timing of task completion. Activities are carried out simultaneously.

\subsection{Avoidance of conflict}

Another issue that was mentioned by all respondents was the perception of the efforts of Czech managers to avoid conflict (99 times). This standard was commented on as either a direct avoidance or avoidance through an excuse, digression from the topic, but also, for example, as a difficulty delegating more tasks to the subordinates. From the perspective of German managers, delegation of responsibilities and following-up on the delegated task could be more developed among their Czech colleagues. This includes all the aspects that delegation involves, including potential conflict. Here are some examples of typical coded incidents.

"We Germans tell each other our opinion or truth much more quickly, regardless of our positions."

"In the Czech Republic, it was common to agree on something, make a decision about something. Basically, we never really argued; we just had a bit of a discussion..."

Or: "In Germany, we plan a lot, but we're not flexible when things do not go according to plan. Czechs are more flexible in this. They (the Czechs) always laugh when we Germans are planning something. They say, we're not going to stick to it anyway, to the plan. But on the other hand, with regard to communication, we Germans love to argue. Sometimes aggressively. That's not common in the Czech Republic, they (the Czechs) are more careful. And more moderate. Regarding the choice of words, etc. The voice. That's agreeable."

Several mentions were made of an overall caution on the part of the Czechs in front of their German colleagues until getting to know them better, or more "personally". Some managers noticed that the closer they got to their Czech colleagues (being on first name terms, shared hobbies, personal affinity), the more direct the communication became, along with increased engagement and openness. This response also implies the diffusion aspect of culture (Trompenaars, 1993), i.e. mixing professional and private activities.

In connection with the tendency to avoid conflict, half of the respondents gave examples of when the original agreement was different from the result itself (14). Their counterpart had interpreted the agreement in his own way either in order to avoid further discussion or, in most cases, because inwardly he did not really fully accept the agreement but felt the issue was not worth causing further conflict. 
"But, I have often experienced that we agreed on something, we said ok, let's do it this way, and eventually everyone did it somehow but then we spent two weeks discussing it again and clarifying why it was done in a different way. I don't understand, we had agreed on something, hadn't we?"

"In Germany a colleague tells you openly that something is nonsense. In the Czech Republic, I have a feeling that unless your relationship with the person is closer and they do not really agree with the project, the thing gets bombed from the side until it stops working." The answers in these cases contained elements of particularism (Trompenaars, 1993 ) manifested here as an unwillingness to follow strict and clearly defined rules and in the fact that social relations are rather specific and more individually-oriented.

\subsection{Rejection of hierarchical structures}

Rejection of hierarchical structures (30 codes) was also commented on in the context of the Czech culture, using an example where Czech managers as professionals in their field lead their relevant departments perfectly. However, at the moment when collaboration begins with other departments, conflicts occur. The most poorly managed of these situations are those involving "well-meant advice", which is seen immediately as inappropriate (personal) criticism. According to the Germans, feedback seen as normal in Germany, was taken almost immediately on a personal level in the Czech Republic.

A German manager's view: "I was slightly more reserved afterwards. Because I had a feeling with some (Czech colleagues) that when I was e.g. giving feedback to other departments, they took it quite personally, thinking that I was telling them they were actually incompetent. I always felt that the criticism was personified. That it is not at all about the content, but about the person. That's why I tended to hold back afterwards."

Or: "In my view, normal harmless critique causes you to have the next five cigarettes on your own until things settle down. And this sometimes takes time." The above example was also parallel coded as "non-differentiation between personal and professional life."

In some interviews, rejecting hierarchical structures manifested itself as an unwillingness to accept German colleagues who were sent to the Czech Republic only for a limited period of time.

"That's where there is a problem in cooperation between Czechs and Germans or maybe foreigners in general. We (Germans) usually come here for a short time, mostly from our headquarters. I believe [a] certain skepticism against us automatically arises here. I think the Czechs are thinking to themselves: 'This one comes from Big Brother, he doesn't like it here in the Czech Republic, all he wants is to get on with his career, he has to be here but doesn't actually want to. And in three years, he is gone. And he doesn't care about us as a team."

"I would call it a Czech empire. Why? Because with really critical decisions, Czech executives suddenly pull together and this alliance is there. It happens, we can feel it, but what always amazes us is how those folks argue among themselves, but for critical issues all disputes are gone and they are together. And in that moment you feel it is Germans or Americans, anyone, standing on one side, and the locals on the other side. Perhaps it's for historical reasons."

According to the respondents in the Czech Republic, it is important to discuss major changes, projects, and strategic decisions in advance with various "interest groups". 
Two managers explicitly expressed that time devoted to informal talks before the start of a project was the best way to invest this time, which should be in some way set aside. This is mainly due to the fact that, if a decision made by a Czech manager is eventually based on his strong conviction and not only a command, the result is better and more stable than might be the case for example in Germany.

Although the Czech culture is generally considered to be a culture with a high communication context, the given standard was not recorded in the interview. Here, it can be assumed that at a higher hierarchical level, communication is explicit (Hall, 1977), and therefore more straightforward.

Another little mentioned cultural standard was "fluctuating self-confidence". This standard was perceived only to a minimal, almost negligible extent among Czech managers. A possible interpretation could be that people in managerial positions are persons with high self-esteem and with clear goals and ability to see things in a larger perspective.

Based on the above arguments, we present the following propositions:

Proposition 1: Czech managers are considered by their Germans counterparts as rather conflict avoiding colleagues, tending rather to find a solution in a calm and peaceful way.

Proposition 2: German managers consider Czech managers as people with a propensity to improvise.

Proposition 3: Czech managers are not always prone to stick to hierarchical structures.

\section{Discussion and Conclusion}

The findings confirm the general description of Czech culture as externally oriented and thus more "philosophizing", collectivist, diffuse, and particularistic (Nový \& SchrollMachl, 2015). The occurrence and enumeration of all standards is consistent with results of previous empirical studies (Schroll-Machl, 2001; Thomas, 1996).

The conducted interviews and confrontations with literature imply that in the interaction between Czech and German managers, all of the defined Czech cultural standards occur. In addition, there are probably several fundamental Czech cultural standards that can be considered crucial for interaction between Czech and German managers. These are cultural standards of avoiding conflict, propensity for improvisation, and rejection of hierarchical structures.

The information based on qualitative research (generalized in this article) and the ensuing facts can be interpreted as a consequence of personal characteristics, cultural patterns, and personal experience. Certain negative influence could be caused by retrospective bias thus tending to evaluate events and situations with a certain preference towards particular perspective or ideology. All of this may affect the results and decrease the reliability of the findings. The simplification and conversion of the occurrence of Czech cultural standards into a schematic set of standards may mean a certain reduction.

For the above reasons, and to prevent possible confusion between the research results and mere stereotypes, it would be necessary to carry out extensive empirical research of a quantitative nature containing several individual investigations related to the given cultural standards. In such research, mutual perception should be identified and general patterns of behavior should be confirmed in a representative sample of German and Czech managers. 
This research should define the number of managers to whom the relevant standard applies and the number of managers who consider the standard to be correct. Also, it should be stated whether they make use of this standard or not.

In mutual interaction, cultural dimensions should always be placed in the context of the given situation as a help enabling better structuring of the behavior of a partner from another culture.

A person or an individual coming into contact with foreign cultures should form their own opinion of the given group of people. The defined cultural standards would only serve as signboards for faster finding of the path toward mutually successful cooperation.

In this context, Demorgon (1989) highlights the need to put these dimensions into the context of general cultural theory. The caution Demorgon shows in his interpretation is not applied to the same extent in the works of Hofstede, Hall, or Trompenaars. Without additional interpretation, this may lead to stereotyping.

This article presents the main authors and works of the classical theory in this field; nevertheless, the references are relatively old. The qualitative research is contributing to the results of similar research which is nowadays also coming from beginning of this century. There are some new similar research and polemic about the applicability of the models in these days mentioned.

This article is intended as a contribution to the debate on the cooperation of Czech-German teams at the managerial level. The semi-structured narrative interviews helped to identify fundamental Czech cultural standards at the management level from the perspective of ten German managers.

The use of qualitative research brings certain restrictions that do not allow the findings to be generalized for the entire population, which, however, was also not the goal of this work. In spite of that, it was only qualitative research via the critical incident method that allowed us to capture the cultural standards which are crucial in effective communication and cooperation between Czechs and Germans.

The results present us with two main findings. Czech managers' ability to improvise is understood by German executives as an exceptional quality which they themselves often do not possess. If this skill is embedded in the structured framework of projects or directly the operational strategy of a department or an organization, this whole creates a significant competitive advantage.

The second key standard from the German managers' point of view is the Czech managers' tendency to avoid conflict. The conflict in this sense, however, is not a personal conflict, which might be what the German manager actually seeks, but an effort to hold expert debate using all available arguments to achieve the best possible result.

With German managers, an expectation of directive and participative communication in mutual communication prevails.

\section{References}

Bedrnová, E., \& Nový, I. (2009). Psychologie a sociologie řízení. Prague: Management Press.

Beugelsdijk, S., Maseland, R., \& van Hoorn, A. (2015). Are Scores on Hofstede's Dimensions of National Culture Stable over Time? A Cohort Analysis. Global Strategy Journal, 5

Demorgon, J. (1989). L'exploration interculturelle. Pour une Pédagogie internationale. Paris: Colin. 
Fink, G., Nový, I., \& Schroll-Machl, S. (2001). Tschechische, österreichische und deutsche Kulturstandards in der Wirtschaftskooperation. Journal for East European Management Studies, 5(4).

Gupta, V., \& Hanges, P. J. (2004). Regional and Climate Clustering of Societal Cultures. In House, R. et al. (Eds.), Culture, Leadership, and Organizations. The GLOBE Study of 62 Societies. Thousand Oaks: Sage.

Hall, E. T. (1985). Hidden Differences: Studies in International Communication. Hamburg: Gruner \& Jahn.

Hall, E. T. (1990). Understanding cultural differences. Yarmouth, ME: Intercultural Press.

Hofstede, G. (1980). Culture's consequences: International differences in work related values. Beverly Hills, CA: Sage.

Hofstede, G., \& Bond, M. H. (1988). The Confucius connection: From cultural roots to economic growth. Organizational dynamics, 16(4), 5-21.

Hofstede, G. (2001). Culture's consequences: comparing values, behaviours, institutions, and organizations across nations. Thousand Oaks: Sage.

Hofstede, G., \& Minkov, M. (2010). Cultures and Organizations: Software of the Mind. 3rd Edition, McGraw-Hill USA, 2010

Hofstede, G. (2016) Cultural standards. Retrieved March 20, 2016 from http://geert-hofstede. com.

Hospodářské vztahy (2016). Česko-německé vztahy [Czech-German relations]. Retrieved March 20, 2016 from http://tschechien.ahk.de/cz/o-nemecku/cesko-nemecke-vztahy.

House, R. J., Wright, N. S., \& Aditia, R. N. (1999). Cross-cultural research on organizational leadership: A critical analysis and proposed theory, In Earley, P. C, \& Erez, M. (Eds.), New perspectives on international industrial/organisational psychology. San Francisco: New Lexington

Minkov, M., \& Hofstede, G. (2014). A replication of Hofstede's uncertainty avoidance dimension across nationally representative samples from Europe. International Journal of Cross Cultural Management, 14(2), 161-171.

de Mooij, M. (2013). On the misuse and misinterpretation of dimensions of national culture. International Marketing Review, 30(3), 253-261.

Nový, I., \& Schroll-Machl, S. (2005). Spolupráce přes hranice kultur. Prague: Management Press.

Nový, I., \& Schroll-Machl, S. (2007). Interkulturní komunikace v řízení a podnikání: Českoněmecká. Prague: Management Press.

Nový, I., \& Schroll-Machl, S. (2015). Interkulturní komunikace: Češi a němci. Prague: Management Press.

Reber, G., Auer-Rizzi, W., \& Maly, M. (2004). The behaviour of managers in Austria and the Czech Republic: an intercultural comparison based on the Vroom/Yetton model of leadership and decision making. Journal for East European Management Studies, 9(4), 411-429.

Schmitz, L., \& Weber, W. (2014). Are Hofstede's dimensions valid? A test for measurement invariance of uncertainty avoidance. Interculture journal: Online-Zeitschrift für Interkulturelle Studien, 13(22), 11-26.

Smith, P. B., Dugan, S., \& Trompenaars, F. (1996). National culture and the values of organizational employees a dimensional analysis across 43 nations. Journal of crosscultural psychology, 27(2), 231-264. 
Thomas, A. (1996). Psychologische Wirksamkeit von Kulturstandards im interkulturellen Handlen. In Thomas, A. (Ed.), Psychologie des interkulturellen Handelns, Göttingen: Hogrefe.

Thomas, A. (2001). Intercultural Training is culture specific interaction process. Journal for East European Management Studies, 5(4).

Trompenaars, F. (1993). Riding the waves of culture: Understanding cultural diversity in business. London: The Economist Books.

Venaik, S., \& Brewer, P. (2013). Critical issues in the Hofstede and GLOBE national culture models. International Marketing Review, 30(5), 469-482.

\section{Authors}

Ing. Karel Kňap, MBA

Ph.D. student

Faculty of Business Administration

University of Economics, Prague

nam. W. Churchilla 4, 130 67, Prague 3

qknak00@vse.cz

prof. Ing. Ivan Nový, CSc.

Dean

Faculty of Business Administration

University of Economics, Prague

nam. W. Churchilla 4, 130 67, Prague 3

ivan.novy@vse.cz 